\title{
Indigenous strains of lactobacilli as a basis for probiotics design
}

\author{
Yuri Kozlovsky ${ }^{1,2}$, Galina Kozlovskaya ${ }^{1}$, Aminat Magomedova ${ }^{1}$, Vasiliy Kozlovsky ${ }^{2}$, and \\ Tatiana Khomyakova, \\ ${ }^{1}$ Federal state budgetary scientific institution «Research Institute of human morphology» Tsyurups, \\ 117418 , st., 3, Moscow, Russia \\ ${ }^{2}$ Scientific research center "Kurchatov Institute" - Gosniigenetika. \\ ${ }^{3}$ Federal state budgetary scientific institution "Research Institute of fur farming and rabbit breeding \\ named after V. A. Afanasyev", 140105, Trudovaya str., 6, village Rodniki, Ramensky, Moscow \\ region, Russia
}

\begin{abstract}
Lactobacilli are the most common microbes used in therapy and farm breeding. Their effectiveness and safety depend on species and strains of bacteria. In this investigation the most importance properties more than two hundred of Lactobacilli strains were studies. They were divided to the groups in dependence of their origin. The antagonistic activity between the members of different groups as well as between Lactobacilli and pathogens and opportunistic microbes were analyzed. It was found that the source of the bacteria determine the adhesive properties, bacterial antagonism and bacteriocins production.
\end{abstract}

\section{Introduction}

The normal gastrointestinal microbiota (normobiota) is an evolutionarily formed community of microorganisms, viruses and protozoa, composed in the process of interaction with the host during the entire period of its existence as a biological species [1]. However, in recent decades a steady increase in the frequency of development of disbiotic disorders of the qualitative and quantitative composition of the normal microbiota has been observed in all parts of the world. The factors that contribute to the violation of the composition of microbiota are the use of medications, stress, adverse environmental conditions, improper diet etc. The members of the concomitant microbiota, "good" Escherichia coli and Lactobacilli sp. are primarily eliminated from the microobiocenosis during antibiotic therapy. From microbiological point of view the characteristic features of disbiosis is the excessive growth of opportunistic and pathogenous microorganisms, replaced normobiota members in their biotopes and colonization in atypical eco-systems. It causes both local and generalized infectious and inflammatory processes in host's body.

* Corresponding author tatkhom $@$ yandex.ru 
The most currently accepted way to correct disbiosis before the stage of stable pathobiome formation is the use of probiotic drugs. The first stage in the development and creation of such drugs is to study the properties of bacterial cultures, followed by the selection of strains that possess a number of properties: antagonistic activity in relation to pathogenic microbiota, realized due to the production of antibacterial substances, changes in the $\mathrm{pH}$ of the environment, which provides a mediated effect on the enzymatic activity of pathogens. Probiotic bacteria must have a pronounced antagonistic activity against pathogenic microorganisms. The concept of antagonistic activity is very broad and consists of many components, including a higher rate of bacterial reproduction, a wider set of enzymes, as well as the production of various bactericidal and bacteriostatic substances [2, 3]. Among these substances, organic fatty acids have a high antagonistic activity against pathogens. In particular, lactobacilli are capable of synthesizing bacteriocins - natural antibiotic-like substances [4, 5]. Bacteriocins produced by lactobacilli (lactobiotics) can inhibit the reproduction of a wide range of microorganisms: Clostridium, Streptococci, Enterobacteria, Listeria, Candida fungi, etc. [6-7].

Competition with pathogenic and opportunistic bacteria for adhesion sites. The ability of probiotic strains to bind to certain receptors on the surface of the gastrointestinal mucosa provides competition for these receptors with pathogenic and opportunistic microorganisms, since the number of such receptors on epithelial cells is limited. This is confirmed by observations indicating that pretreatment of targets with Cohn lectin or bacterial adhesives drastically reduces the number of microorganisms that can fix on the preliminary incubated cells. It is believed that adherent probiotic bacteria "block" eukaryotic cell receptors, making them unavailable for binding to pathogenic agents. The value of adhesive strains for creating probiotic drugs lies not only in their ability to longterm persistence in the gastrointestinal tract, but also in competition with pathogens for adhesion sites on the surface of enterocytes. A number of studies have shown that the oral administration of lactobacilli with distinct adhesion leads to a significant decrease in the number of E. coli colonizing the intestines of chickens [5, 8]. It was proved that Lactobacillus species with probiotic property can be used in poultry feed formulation for their health benefit to combat gastrointestinal infections. [9]. Bacteria of the genus Lactobacillus can prevent colonization of the vaginal epithelium by uropathogens (PS. aeruginosa, Enterococcus sp., Klebsiella pneumoniae, E. coli) [10], it also binds glycolipid receptors of Helicobacter pylory [11]. The reduced adhesion of intestinal pathogens. carrying S-fimbria on their surface, when using Lactobacillus was also shown [12].

The used strains should not inhibit the growth of indigenous microbiota. It was previously shown that the pharmacy probiotics, designed on the basis of the allogenic strains, can displace the indigenes strains of the host and induce the inflammation in the gut.

The aim of the work was the comparative analysis of the strains isolated out of different sources for the following drug construction. The effective and safe probiotics should adhere to the wall of he gut, successfully cooperate with the host's "useful" microbiota and suppress pathogens.

\section{Materials and methods}

206 strains of bacteria belonging to different species of the genus Lactobacilli isolated from various sources (dairy and vegetable origin, as well as the gastrointestinal tract) were used. MRS medium (HiMedia, India) was used as a selective culture medium for isolation and cultivation of lactobacilli. To improve the growth of Lactobacilli cultivation of bacterial strains was carried out in an anaerostat at $5 \% \mathrm{CO}_{2}, 37^{\circ} \mathrm{C}$. For the cultivation of Enterobacteria, Pseudomonas, and cocci, we used an agarized medium of Luria-Bertani of 
the following composition: peptone $10 \mathrm{~g}$, yeast extract $5 \mathrm{~g}$, sodium chloride $10 \mathrm{~g}$, dispersed in distilled water up to $1000 \mathrm{ml}$. Cultivation of pathogenic and opportunistic bacteria was carried out at $37^{\circ} \mathrm{C}$ in a dry air thermostat.

Kits for DNA and RNA isolation as well as conduction a real-time_polymerase chain reaction (Isogen \&Eurogen (Russia)) were used.

All manipulations were carried out in accordance with the recommendations of manufacturers. Species-specific primers for the species determination of lactobacilli were synthesized by Eurogen(Russia). The list of primers is shown in Table 1.

Table 1. The list of used primers

\begin{tabular}{|c|c|}
\hline Bacterial species & Primers base composition \\
\hline $\begin{array}{c}\text { Lactobacillus sp } \\
\text { (common) }\end{array}$ & TTGAAACAGRTGCTAATACCG \\
& GYCCATTGTGGAAGATTCCC \\
\hline L plantarum & CTCTGGTATTGATTGGTGCTTGCAT \\
& GTTCGCCACTCACTCAAATGTAAA \\
\hline L. reuteri & GAACGCAYTGGCCCAA \\
& TCCATTGTGGCCGATCAGT \\
\hline L.brevis & ATTTTGTTTGAAAGGTGGCTTCGG \\
& ACCCTTGAACAGTTACTCTCAAAGG \\
\hline L.fermentum & CCTGATTGATTTTGGTCGCCAAC \\
& ACGTATGAACAGTTACTCTCATACGT \\
\hline L.rhamnosis & TGCTTGCATCTTGATTTAATTTTG \\
& TTGTCTTGGATYTATGCGGTATTAG \\
\hline L, casei & CCGACAACAGTTACTCTGCC \\
& ACCGCATGGTCTTGGC \\
\hline
\end{tabular}

Adhesive properties of lactobacilli were studied in vitro on the model of formalinized red blood cells (RBC) by V. Brilis (1984) in the modification adopted in our laboratory. The experiments used bacterial suspensions at a concentration of $2 \times 10^{9} \mathrm{CFU} / \mathrm{ml}, \mathrm{RBC}$ at a concentration of $2 \times 10^{8}$ cells $/ \mathrm{ml}$. The concentration of $\mathrm{RBC}$ was calculated in the Goryaev's chamber under a light microscopy. The concentration of microbial cell suspension was determined by the optical density at $560 \mathrm{~nm} .0 .5 \mathrm{ml}$ of a suspension of RBC and microbial cells was mixed, incubated for 45 minutes at $37^{\circ} \mathrm{C}$, periodically shaking. The drop of suspension was put on the object-plate for getting thin film, dried and painted with Romanovsky-Gimza dye. The mean value of adhesion index was determined by the average number of microbes adhering to the surface of one red blood cell. All available erythrocytes in 5 visual fields were counted, but not less than 50 cells. The percentage of red blood cells with bacterial cells on their surfaces was calculated in relation to the total number of erythrocytes taken into account $(\mathrm{K} \%)$. 
The antagonistic activity of lactobacilli in relation to pathogenic and opportunistic microorganisms was studied using the agar block method. It was interesting to find out the nature of this antagonism and first of all to study the possibility of antagonism between the strains of different strains of lactobacilli with different origin. To study antagonistic relationships between members of the genus Lactobacilli, the method of two-layer agar was used as exemplified by Doyle M.P. et al [13]. Many factors can cause antagonistic interactions between different microorganisms, such as the synthesis of antibiotics, the formation of peroxides, organic acids, alcohols, lysozyme, and other biologically active substances with antibacterial activity [14].

Lactobiotiics were isolated using ethylacetate adding. Lactobiotics are the lactobacilliproduced substances possessed the bacteriocines. To limit the number of strains tested for the production of lactobiotics, only strains that showed antagonistic activity in previous studies were used in this step of the experiment. Lactobacilli were cultivated in a liquid culture medium MRS during 48 hours at $37^{\circ} \mathrm{C}$ and then mixed with ethylacetate with following incubation 36 hours with constant stirring. After that the mixture was centrifuged at $10,000 \mathrm{rpm} 20$ minutes and supernatant containing lactobiotics was taken. The supernatant was lyophilized, dissolved in distilled water and applied $10 \mu \mathrm{l}$ on sterile paper disks, which were placed on a freshly sown lawn of the test- strain E. coli, P. mirabilis, $P$. aeruginosa, $S$. pyogenes, and $S$. aureus at the plates with solid medium The colonies were counted after 24 hours of incubation at $37^{\circ} \mathrm{C}$.

\section{Results and discussion}

\subsection{Identification of Lactobacillus strains.}

Previously isolated Lactobacillus strains were identified by real-time PCR. All strains were divided into four groups in dependency of their origin, their composition is presented in Table 2

Table 2. The strains of four groups in dependency of their origin

\begin{tabular}{|c|c|c|c|c|c|}
\hline & $\begin{array}{l}\text { Group } \\
\text { I }\end{array}$ & Group II & Group III & Croup IV & $\begin{array}{l}\text { Number } \\
\text { of the } \\
\text { strains }\end{array}$ \\
\hline Origine & $\begin{array}{l}\text { cultured } \\
\text { milk } \\
\text { foods }\end{array}$ & $\begin{array}{l}\text { plant } \\
\text { fermentation } \\
\text { products }\end{array}$ & $\begin{array}{l}\text { lumen of } \\
\text { gastrointestinal } \\
\text { tract of } \\
\text { animals }\end{array}$ & $\begin{array}{l}\text { wall of } \\
\text { gastrointestinal } \\
\text { tract of } \\
\text { animals }\end{array}$ & \\
\hline $\begin{array}{l}\text { Common } \\
\text { number }\end{array}$ & $\begin{array}{l}44 \\
\text { strains }\end{array}$ & 41 strains & 51 strains & 70 strains & 206 \\
\hline L. casei & $\begin{array}{l}24 \\
\text { strains }\end{array}$ & 6 strains & 11 strains & 12 strains & 53 \\
\hline L.plantarum & $\begin{array}{l}12 \\
\text { strains }\end{array}$ & 27 strains & 14 strains & 17 strains & 70 \\
\hline $\begin{array}{l}\mathrm{L} \\
\text { rhamnosum }\end{array}$ & $\begin{array}{l}8 \\
\text { strains }\end{array}$ & - & 9 strains & 14 strains & 31 \\
\hline L. brevis & $\begin{array}{l}7 \\
\text { strains }\end{array}$ & - & 10 strains & 10 strains & 27 \\
\hline $\begin{array}{l}\text { L. } \\
\text { fermentum }\end{array}$ & - & 1 strain & 7 strains & 10 strains & 18 \\
\hline L. reuteri & - & - & - & 7 strains & 7 \\
\hline
\end{tabular}




\subsection{The study of the adhesive properties of Lactobacillus strains}

The ability to adhere is one of the main factors contributing to the long-term persistence of probiotic strains in the gastrointestinal tract, The first stage of our study was the study of the adhesive properties of lactobacilli on the model of RBC treated with formalin. Almost all strains had the ability to adhere to RBC. The highest values of adhesion index and $\mathrm{K} \%$ (adhesion coefficient) were determined for the strains isolated from the gastrointestinal tract of animals. Strains isolated from cultured milk foods and plant fermentation products have shown a low adhesive activity (Fig. 1), the ability to adhere significantly differed in groups depending on their origin.

In general, as expected, Lactobacillus strains isolated from the gastrointestinal tract were the most adhesive. Somewhat unexpected is the fact that the strains related to the lumen and wall microbiota practically did not differ in their adhesive properties. At the same time, lactobacilli isolated from cultured milk foods as well as plant sources were less adhesive. The transient nature of the action of many probiotics created on the basis of lactobacilli isolated from abiotic sources [15] makes it necessary to pay more attention to the study of the adhesive properties of non-pathogenic bacteria used in the construction of bacterial preparations.

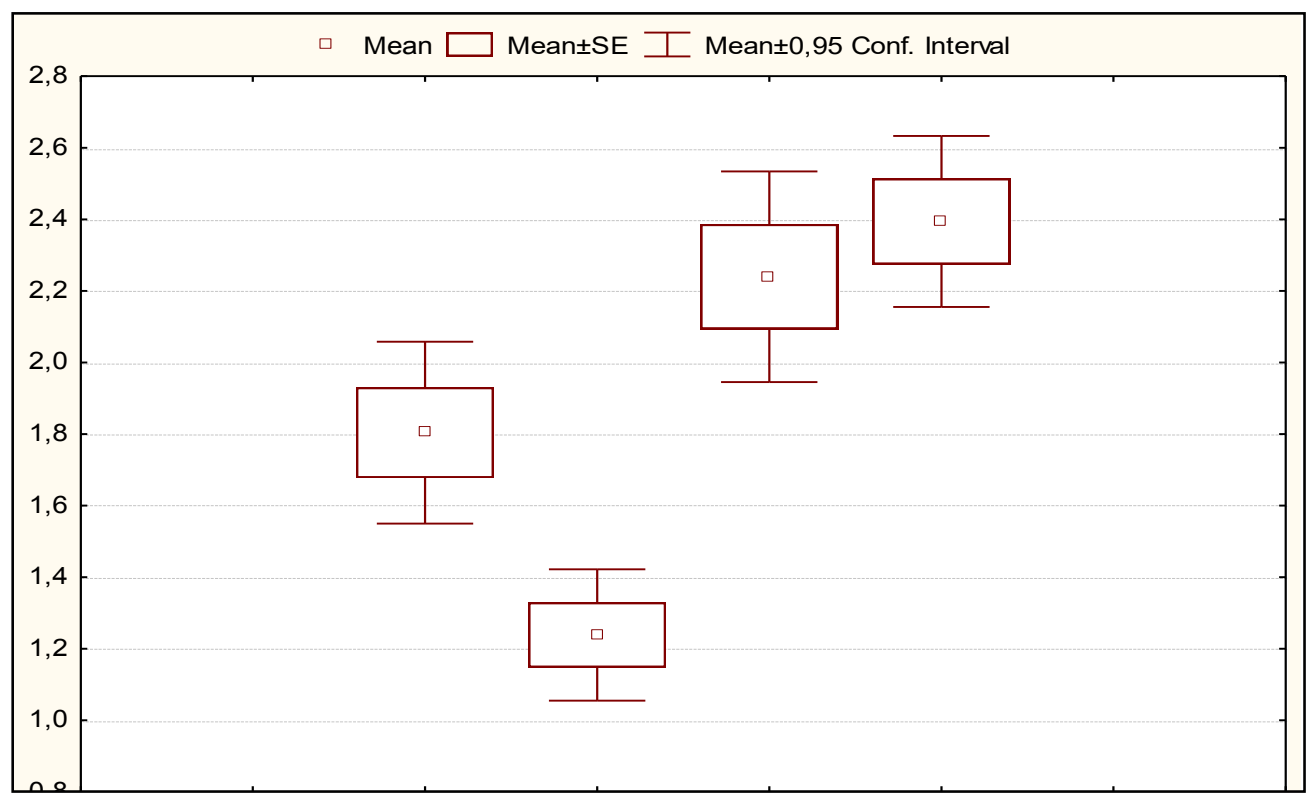

Group I Group II Group III Group IV

Fig. 1. Comparison of adhesive properties of strains isolated from different sources. The mean value of adhesion index is on the ordinate axis

\subsection{The study of lactobacilli antagonism to pathogenic and opportunistic microbes}

One of the main characteristics of probiotics is their ability to suppress pathogenic and opportunistic microbiota. Therefore, the next stage of our research was to study the effect of Lactobacillus strains on of pathogenic and opportunistic bacteria using the agar block 
method. The index of antagonistic activity was presented as a fraction with the number of strains that inhibit the growth of test strains in nominator. He total number of strains in the group is in the denominator. The results are shown in Table 3.

Table 3. Lactobacilli antagonism to pathogenic and opportunistic microorganisms

\begin{tabular}{|c|c|c|c|c|c|}
\hline \multirow{2}{*}{$\begin{array}{c}\text { Group of } \\
\text { lactobacilli }\end{array}$} & \multicolumn{5}{|c|}{ Test strains } \\
\cline { 2 - 6 } & E. coli & P. mirabilis & P.aeruginosa & S. pyogenes & S. aureus \\
\hline Group I & $17 / 44$ & $8 / 44$ & $2 / 44$ & $21 / 44$ & $11 / 44$ \\
\hline Group II & $8 / 41$ & $3 / 41$ & $0 / 41$ & $12 / 41$ & $4 / 41$ \\
\hline Group III & $3 / 51$ & $1 / 51$ & $1 / 51$ & $7 / 51$ & $2 / 51$ \\
\hline Group IV & $4 / 70$ & $0 / 70$ & $0 / 70$ & $7 / 70$ & $1 / 70$ \\
\hline
\end{tabular}

Lactobacillus strains isolated from cultured milk foods and fermented plant materials suppressed the growth of test cultures the most actively. Among the strains isolated from the gastrointestinal tract of animals, the strains with pronounced antagonistic activity were determined much less common. The most sensitive test culture was $S$. pyogenes, and the most stable was $P$. aeruginosa.

The study of the relationship between strains of lactobacilli isolated from different sources. When developing complex probiotic preparations, it is necessary to take into account both the compatibility of the strains included in one preparation, and their effect on the indigenous microbiota. In our study the strains isolated from the gastrointestinal tract were used as indigenous strains. The methods of perpendicular striations and delayed antagonism were used to study the relationship between strains of lactobacilli. The results are summarized in Table 4. The numerator shows the number of strains suppressed by the members of this group. The denominator is the total number of strains in the group

Table 4. The results of the study of the relationship between strains of lactobacilli isolated from different sources

\begin{tabular}{|l|l|l|l|l|}
\hline Strains & Group I & Group II & Group III & Group IV \\
\hline Group I & - & $26 / 52$ & $32 / 52$ & $34 / 52$ \\
\hline Group II & $12 / 41$ & - & $29 / 41$ & $33 / 41$ \\
\hline Group III & $3 / 51$ & $3 / 51$ & - & $3 / 51$ \\
\hline Group IV & $2 / 70$ & $5 / 70$ & $5 / 70$ & - \\
\hline
\end{tabular}

The table shows that the greatest antagonism to taxonomically close microorganisms is shown by strains isolated from fermented milk products and plant materials. At the same time, strains from the gastrointestinal tract are more sensitive to the action of antagonist strains. Lactobacillus strains isolated from cultured milk foods and fermented plant materials suppressed the growth of test cultures the most actively. Among the strains isolated from the gastrointestinal tract of animals, the strains with pronounced antagonistic activity were determined much less common. 


\subsection{The study of the production of lactobiotics}

For the ability to synthesize lactobiotics, 49 strains of lactobacilli were tested, which showed antagonism to at least one of the test strains in previous experiments. The ability to produce lactobiotics was demonstrated only by 7 of them. The zones of suppression of the growth of the test culture, formed around the discs, with the applied extracts of the studied strains statistically differed. In experiments on the cross-study of producer strains, it was shown that 7 active strains produce 3 types of lactobiotics. Moreover, one of them identified as Lactobacillus casei, identified 2 different species of lactobiotics.

\section{Conclusion}

The ability to adhere, the possibility to produce lactobiotics, the competition activity and apparently other properties significantly differed in groups depending on their origin. Lactobacillus strains isolated from the gastrointestinal tract were the most adhesive. Lactobacilli isolated from cultured milk foods as well as plant sources were less adhesive. The greatest antagonism to taxonomically close microorganisms is shown by strains isolated from fermented milk products and plant materials. At the same time, strains from the gastrointestinal tract are more sensitive to the action of antagonist strains. The ability to produce lactobiotics was demonstrated only by 7 strains.

The creation the new effective and safe probiotic preparation on the basis of lactobacilli should use the biotic sources, microbes must be friendly to indigene lactobacilli and active against pathogens and opportunistic infections and posses a good adhesive properties.

\section{References}

1. S. Talebi, A. Makhdoumi, M. Bahreini, M. M. Matin, H. S.Moradi, J Appl Microbiol., 125(3), 888-896 (2018) doi: 10.1111/jam.13901. Epub 2018 Jun 26

2. S. Byakika, I. M. Mukisa, Y. B. Byaruhanga, C. Muyanja, Int J Microbiol, 4, 7825943 (2020) doi: 10.1155/2020/7825943. eCollection 2020.

3. M. M. Abomughaid. Int J Microbiol, 17, 8865456 (2020) doi: 10.1155/2020/8865456. eCollection 2020.

4. S. Spriewald, E. Stadler, B. A. Hense, P. C. Münch, A. C. McHardy, A. S. Weiss, N. Obeng, J. Müller, B. Stecher, mBio. 21, 11(4), e00912-20 (2020) doi: 10.1128/mBio.00912-20.

5. W. P. J. Smith, A. Vettiger, J. Winter, T. Ryser, L. E. Comstock, M. Basler, K. R. Foster. PLoS Biol. 26, 18(5), e3000720 (2020) doi: 10.1371/journal.pbio.3000720

6. W. P. J. Smith, A. Vettiger, J. Winter, T. Ryser, L. E. Comstock, M. Basler, K. R. Foster, J Appl Microbiol., 126(5), 1541-550 (2019) doi:10.1111/jam.14164

7. O. V. Rybalchenko, V. M. Bondarenko, O. G. Orlova, A. G. Markov, S. Amasheh, A. Microbiol, 197(8), 1027-1032 (2015) doi:10.1007/s00203-015-1140-1

8. J. M. Pizano, C. B. Williamson, K. E. Dolan, C. M. Gossard, C. M. Burns , M. G. Gasta, H. J. Finley, E. C. Parker, E. A. Lipski, Integr Med. 16(5), $46-57$ (2017) PMID: 30936805

9. Z. Ahmed, M. S. Vohra, M. N. Khan, A. Ahmed, T. A. Khan, J. Infect Dev Ctries, 28, 13(2), 130-136 (2019) doi: 10.3855/jidc.10542. PMID: 32036348.

10. D. G. de Llano, M. V. Moreno-Arribas, B. Bartolomé, Molecules, 1, 25(15), 3523 (2020) doi: 10.3390/molecules25153523. 
11. F. Hao-Ran, Z. Guo-Qiang, C. Jing-Yi, L. Zhong-Yue, Eur J Pediatr. 178(1), 7-16 (2019) doi:10.1007/s00431-018-3282-Z

12. S. K. Tiwari, L. M. T. Dicks, I. V. Popov, A. Karaseva, A. M. Ermakov, A. Suvorov, J. R. Tagg, R. Weeks, M. L. Chikindas, Front Microbiol, 20, 11, 1877 (2020) doi: 10.3389/fmicb.2020.01877.

13. M. P. Doyle, T. Zhao, B. G. Harmon, C. A. Brown, PubChem [Internet]. Bethesda (MD): National Library of Medicine (US), National Center for Biotechnology Information; PubChem Patent Summary for WO-9908532-A1 (2004) https://pubchem.ncbi.nlm.nih.gov/patent/WO-9908532-A1 (Last accessed 11.06.2020)

14. P. Khemariya, S. Singh, N. Jaiswal, S. N.s. Chaurasia, Food Biotechnology, 30, 49-62 (2016) doi: 10.1080/08905436.2015.1132428.

15. D. Alp, H. Kuleaşan, World J Microbiol Biotechnol, 1, 35(10), 156 (2019) doi: 10.1007/s11274-019-2730-x. 